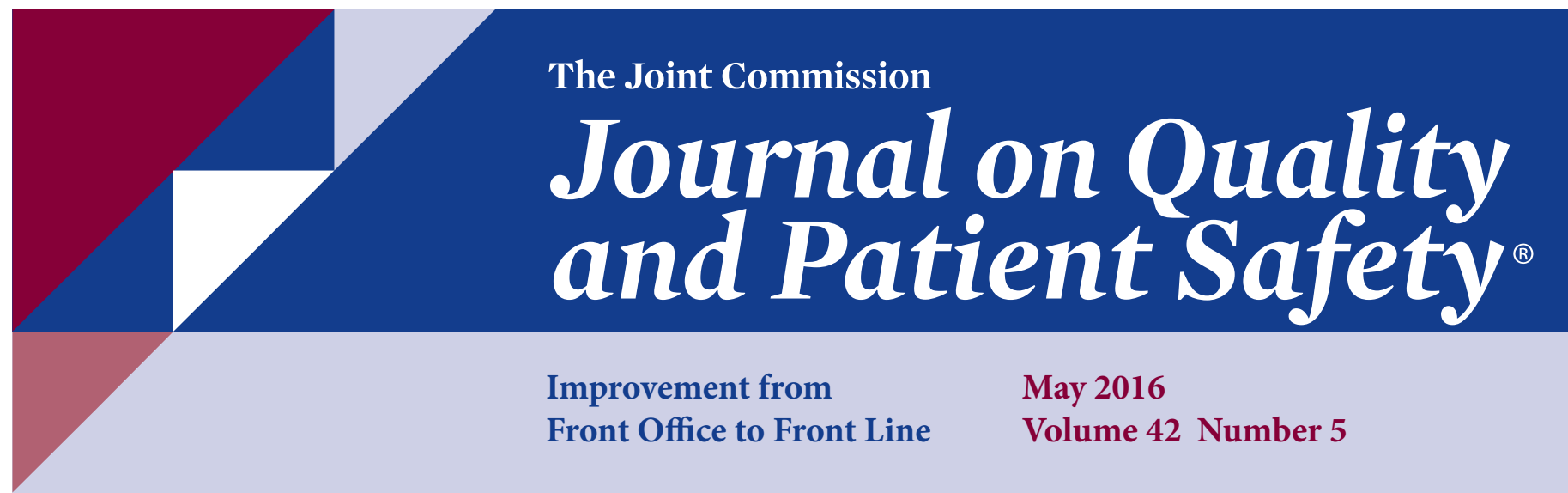

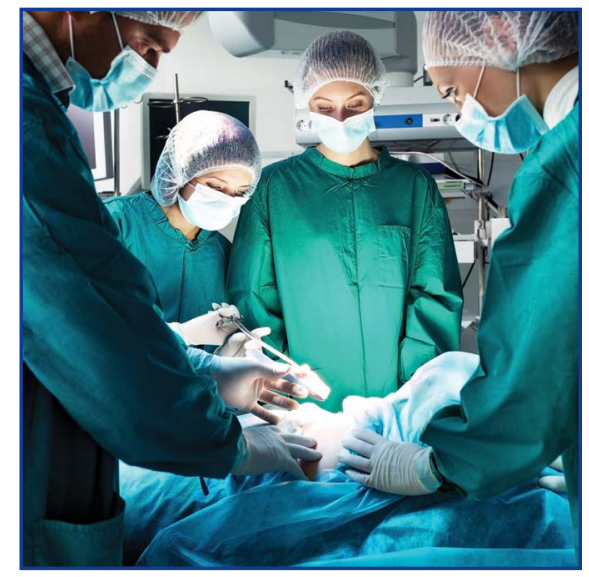

"The standard of reporting of quality interventions and QI techniques in surgery is often suboptimal, making it difficult to determine whether an intervention can be replicated and used to deliver a positive effect in another setting."

- How Well Is Quality Improvement Described in the Perioperative Care Literature? A Systematic Review (p. 196)

Joint Commission Resources

\section{Making Room for}

\section{Improvement in Reporting of QI Studies}

\section{Features}

\section{Performance Improvement}

- Reporting Quality Improvement Interventions: A Call to Action

- How Well Is Quality Improvement Described in the Perioperative Care Literature? A Systematic Review

\section{Performance Measures}

- Will Hospitals Finally "Do the Right Thing”? Providing EvidenceBased Tobacco Dependence Treatments to Hospitalized Patients Who Smoke

- Two Years in the Life of a University Hospital Tobacco Cessation Service: Recommendations for Improving the Quality of Referrals

- Improving Quality of Care for Hospitalized Smokers with HIV: Tobacco Dependence Treatment Referral and Utilization

\section{Methods, Tools, and Strategies}

- Anatomy of Inpatient Falls: Examining Fall Events Captured by Depth-Sensor Technolog

\section{Departments Tool Tutorial}

- Development and Implementation of an Early-Onset Sepsis Calculator to Guide Antibiotic Management in Late Preterm and Term Neonates 
The Joint Commission Journal on Quality and Patient Safety

\title{
Performance Improvement
}

\section{How Well Is Quality Improvement Described in the Perioperative Care Literature? A Systematic Review}

\author{
Emma L. Jones, MSc; Nicholas Lees, MBChB, FRCA, FFICM; Graham Martin, MA (Oxon), MSc, PhD; \\ Mary Dixon-Woods, BA, DipStat, MSc, DPhil
}

$\mathrm{H}$ ealth care is increasingly the subject of quality improvement (QI), ${ }^{1}$ which can be understood as purposeful efforts to make changes that will lead to better patient outcomes, better system performance, and better professional development. ${ }^{2} \mathrm{QI}$ efforts often involve a quality intervention (specific changes to clinical or organizational systems) and a QI technique (a method used to support the implementation of the intervention, such as the Model for Improvement). ${ }^{3}$ Surgery is a particularly important area for QI. Fourteen record-review studies together indicated that adverse events occurred in $14.4 \%$ of 16,424 patients undergoing surgery and that potentially preventable adverse events occurred in 5.2\% of them. ${ }^{4}$ For $3.6 \%$ of the 16,424 patients, the consequences were fatal, and for around $10.4 \%$, severe. ${ }^{4}$ In the United State, adverse events in surgery account for approximately half (48\%) of all adverse events in hospitals. ${ }^{5}$ Given that an estimated 234 million surgical interventions are performed every year worldwide, ${ }^{6}$ improving quality and safety of surgical care is a global priority. ${ }^{7}$

Perioperative care, which encompasses care delivered before, during, and after surgery, ${ }^{1}$ makes an important contribution to the outcomes and experiences of surgery. Systematic reviews of QI efforts in diverse surgical specialties have reported that improvements are possible across the entire perioperative journey. ${ }^{1,8-11}$ However, like randomized controlled trials (RCTs) in surgery, ${ }^{12}$ there are indications that important information may be missing from reports of surgical QI studies. ${ }^{13}$ This is not a problem unique to surgery: Notwithstanding relevant guidance, ${ }^{14}$ reporting of QI is often weak, lacking, for example, details of implementation context, potential harm from QI activities, intervention components, and the duration of individual Plan-Do-Study-Act (PDSA) cycles. ${ }^{15,16}$

One challenge in producing full and explicit accounts of interventions-QI or otherwise-has been the absence of clearly articulated expectations about what should be reported. A welcome recent development, therefore, is the TIDieR (Template for Intervention Description and Replication) checklist, ${ }^{17}$ which identifies 12 features of interventions that studies

\section{Article-at-a-Glance}

Background: Quality improvement (QI) approaches are widely used across health care, but how well they are reported in the academic literature is not clear. A systematic review was conducted to assess the completeness of reporting of QI interventions and techniques in the field of perioperative care. Methods: Searches were conducted using Medline, Scopus, the Cochrane Central Register of Controlled Trials, the Cochrane Effective Practice and Organization of Care database, and PubMed. Two independent reviewers used the Template for Intervention Description and Replication (TIDieR) checklist, which identifies 12 features of interventions that studies should describe (for example, How: the interventions were delivered [e.g., face to face, internet]), When and how much: duration, dose, intensity), to assign scores for each included article. Articles were also scored against a small number of additional criteria relevant to QI.

Results: The search identified 16,103 abstracts from databases and 19 from other sources. Following review, full-text was obtained for 223 articles, 100 of which met the criteria for inclusion. Completeness of reporting of QI in the perioperative care literature was variable. Only one article was judged fully complete against the 11 TIDieR items used. The mean TIDieR score across the 100 included articles was 6.31 (of a maximum 11). More than a third $(35 \%)$ of the articles scored 5 or lower. Particularly problematic was reporting of fidelity (absent in $74 \%$ of articles) and whether any modifications were made to the intervention (absent in $73 \%$ of articles).

Conclusions: The standard of reporting of quality interventions and QI techniques in surgery is often suboptimal, making it difficult to determine whether an intervention can be replicated and used to deliver a positive effect in another setting. This suggests a need to explore how reporting practices could be improved. 


\section{The Joint Commission Journal on Quality and Patient Safety}

should describe. TIDieR is recommended by the Enhancing the QUAlity and Transparency Of health Research (EQUATOR) Network $^{18}$ as an extension of the Consolidated Standards of Reporting Trials (CONSORT) ${ }^{19}$ and Standard Protocol Items: Recommendations for Interventional Trials (SPIRIT) ${ }^{20}$ statements to improve reporting across all "evaluative" study designs. A second challenge in QI reporting is the wide variation in study design used in the field. QI studies can be heuristically distinguished as QI projects, which are characteristically conducted with the primary aim of securing change in a defined service using structured methods, or research and evaluation studies, which are conducted with the primary aim of generating knowledge. ${ }^{21}$ QI projects and research and evaluation studies may use broadly similar methods-for example, in the data-analysis techniques they apply — but they differ in their aims, assumptions about process, and the nature of the claims that they make about generalizability. Thus, for both QI projects and research/evaluation studies, the study design used may affect how both quality interventions and QI techniques are reported. ${ }^{22,23}$ Many study designs used in the improvement field are vulnerable to problems of both internal and external validity (including QI projects and many trial designs, for example) and thus require detailed reporting not just of the "nuts and bolts" of quality interventions and QI techniques, such as what was delivered and by whom, but also of the contextual factors (such as QI team, QI support and capacity, and organization) relevant to implementation. ${ }^{24}$

Poor reporting frustrates improvement in health care systems: Among other problems, it poses threats to the internal validity of studies (for example, by making it difficult to determine the components and mechanisms of the intervention under study and the relevant aspects of context) and to external validity (that is, the ability to replicate in other settings). ${ }^{25,26}$ Yet how well QI in surgery is reported is not known. We aimed to assess, using systematic review methods, the completeness of reporting of quality interventions and QI techniques in the perioperative literature, and, in particular, to identify which elements of reporting are most frequently missing.

\section{Methods}

\section{Protocol}

The protocol describing the design of this systematic review was submitted for external peer review ${ }^{27}$ and was registered with PROSPERO, an international database of prospectively registered systematic reviews in health and social care ${ }^{28}$ (CRD42014012845).

\section{Eligibility Criteria}

In this systematic review, we sought to include the following:

- All studies published (including those published online ahead of print) between January 1, 2000, and May 28, 2014, so as to capture articles indexed since the publication of the Institute of Medicine report To Err Is Human: Building a Safer Health System ${ }^{29}$

- Studies reporting a deliberate effort to produce change in active perioperative care and meeting the criteria for QI as specified in a modified version of a taxonomy generated by Shojania et al. ${ }^{30}$ (Table 1 , page 198)

- All surgical specialties

- Adult surgical services

- Elective and emergency (trauma) surgery

- Primary and secondary care

- Qualitative and quantitative literature

The exclusion criteria were as follows:

- Clinical audits, unless they explicitly reported on the implementation of a QI technique designed to produce and evaluate a change

- Qualitative articles reporting exclusively on staff or patient experience of QI

- Articles reporting on screening and diagnostic techniques such as endoscopy

- Articles reporting on end-of-life care

- Articles not published in English

- Abstracts, conference proceedings, and editorials

- Cadaver studies

- Pediatric studies

\section{InClusion and Classification Decisions}

Determining what qualifies as a "quality improvement" study (and what does not) is far from straightforward. Many complex interventions, such as surgical care pathways, have features in common with QI, particularly when they combine multiple known preoperative, intraoperative, and postoperative elements into a care system. However, not all complex interventions are quality interventions, and not all interventions to improve quality of care involve QI. To aid in classification of studies as "QI" or not, we used a taxonomy based primarily on that developed by Shojania et al. ${ }^{30}$ which itself was built on other well-established taxonomies of behavior change interventions. ${ }^{31-35}$

The taxonomy created by Shojania et al. identifies nine QI "strategies," but, as we recognize, those strategies are of different kinds_-ranging from reminder systems to financial incentives. ${ }^{30}$ We therefore found it useful to distinguish between quality interventions and QI techniques. We defined quality interventions 


\section{The Joint Commission Journal on Quality and Patient Safety}

Table 1. Quality Improvement (QI) Taxonomy*

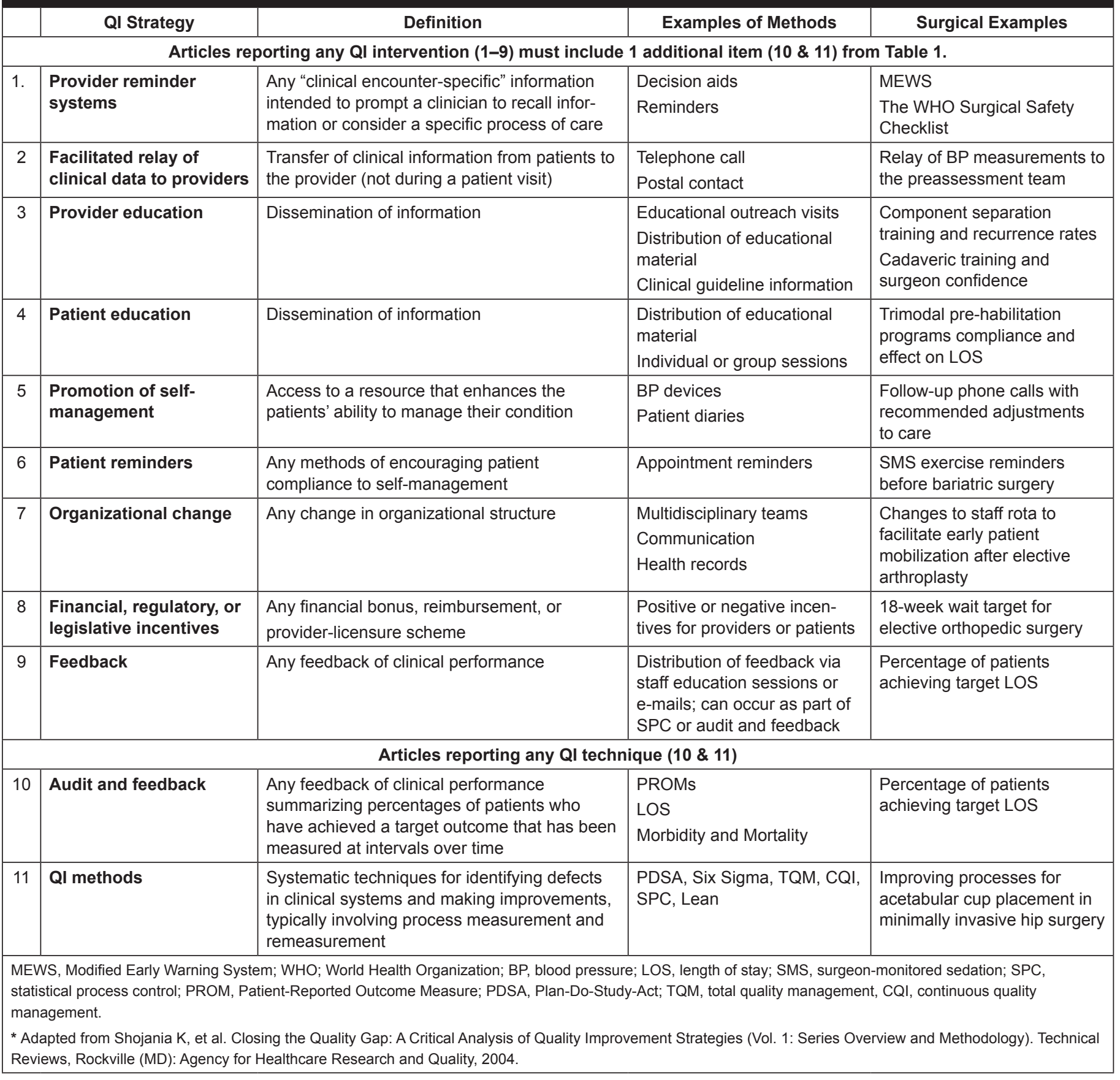

as specific changes to clinical or organizational systems. We defined QI techniques as the methods used to support the change, characteristically involving a predefined set of steps. Thus, while a reminder system for hand washing would be classified as a quality intervention, methods such as PDSA cycles, which are intended to support the implementation of the reminder system, would be classified as QI techniques. Accordingly, we mod- ified the Shojania et al. taxonomy ${ }^{30}$ by classifying the strategies numbered 1 through 9 as examples of quality interventions and those numbered 10 and 11 as QI techniques (Table 1). Of note, the distinction between a quality intervention and a QI technique is not hard and fast but is rather more of a heuristic and is, to some extent, context specific. For example, feedback is listed within the taxonomy as both an intervention and a technique 


\section{The Joint Commission Journal on Quality and Patient Safety}

because feedback can be delivered as part of a quality intervention such as a reminder system but can also be delivered as part a QI technique, such as audit and feedback.

To qualify for inclusion in this systematic review, articles had to report both a quality intervention (strategies 1-9, Table 1) and an associated QI technique (strategies 10 and 11, Table 1). To ensure that use of the modified taxonomy resulted in reliable classification of articles, an article selection training exercise was conducted between three of the authors- known as the reviewers. Author1 [E.L.J.] and Author4 [M.D-W.] considered selected full-text articles for inclusion, and discrepancies were resolved by Author3 [G.M.] Selection criteria were refined to ensure consensus and reliability.

We sought to improve agreement on whether candidate articles met the inclusion criteria by discussing the interventions described in articles with experts in the field and by contacting authors when clarification was needed to classify study design and the type of intervention. ${ }^{36}$

\section{SeARCh STrategy}

Bibliographic databases were selected for their representation of both surgical and QI literature. The Ovid SP version of Medline and Scopus was searched on May 28, 2014. The Cochrane Central Register of Controlled Trials and the Cochrane Effective Practice and Organisation of Care (EPOC) database (which indexes interventional studies focused on improvement in health care delivery) were searched in August 2014 using the terms quality improvement, and quality improvement in surgery" applying the limit of trials. The "related articles" function of PubMed was also searched.

The search strategy (Appendix 1, available in online article) was designed by the three reviewers [E.L.J., G.M., M.D-W.]. In an attempt to design a search that would be sensitive enough to ensure retrieval of all relevant studies and specific enough to ensure that irrelevant articles would be excluded, we adapted a QI search strategy that had previously been used by the Health Foundation in a research scan for literature available as of December 2010 on the concept and practice of improvement science. ${ }^{37}$

Our search strategy was designed to capture terms relating to (1) surgery, (2) quality improvement, and (3) methodology. Medical Subject Headings (MeSH) terms, search terms, thesaurus mapping, and Boolean operators were used. Pilot tests were conducted to ensure that a selection of known surgical QI articles (already identified by a systematic review by Nicolay et al. ${ }^{1}$ on QI in surgery) would be captured by our strategy. The term quality adj2 improv\$ was used to capture QI article (the abbreviated term $Q I$ was not suitable as a search term).

The search strategy [conducted by E.L.J.] applied the restrictions of publication year (2000-2014), humans NOT animals, and NOT infants.

The search results were supplemented with hand searching [by E.L.J.] of the reference lists of full-text articles and of a recently published systematic review on the application of QI methodologies to surgery. ${ }^{1}$ Articles were included unless they were published before January 1, 2000, or included pediatric cases.

\section{Data Extraction}

Data from articles that met the inclusion criteria were extracted onto a Microsoft Excel (Microsoft; Redmond, Washington) spreadsheet [by E.L.J.] using a standardized template based on items from the TIDieR checklist and a checklist containing a small number of additional features relevant to QI (Table 2, page 200).

\section{Use of The TIDieR Checklist to Assess Reporting OF QUALITY INTERVENTIONS}

The QI interventions (items 1-9, Table 1) were scored using a modified version of the TIDieR checklist (Table 2), which contains 12 items relating to reporting criteria. ${ }^{38}$ Item 9 (tailoring: personalization or titration of the intervention) was removed for purposes of this review because the interventions we studied were not titrated for individual patients. This resulted in a modified TIDieR checklist with 11 items, so that the maximum score that could be obtained by any article was $11 / 11$. Scoring was guided by the TIDieR group's explanatory statement, ${ }^{17}$ which was further clarified through e-mail correspondence with TIDieR's first author (Hoffmann).

Articles were scored as "Yes" for each item that could be assessed as reported in full. If the description was unclear or if no description was given, the article was scored as "No" for that item. For example, when an article clearly described the modifications made to an intervention in a manner judged to be fully explicit, it was rated "Yes" under the TIDieR item "modification" (item 9, column 2, Table 2). An example of an article achieving "Yes" under this criterion described the modifications made as follows: "After multiple trials of various insulin protocols, a simplified high-infusion protocol replaced the low-infusion protocol with intermittent boluses." ${ }^{\text {"9 }}$ (p. 25) Many articles reported on multiple interventions, such as a safety bundle. ${ }^{40}$ To accurately replicate a multifaceted program, all its components needed to be fully described. Therefore, we scored each 


\section{The Joint Commission Journal on Quality and Patient Safety}

Table 2. Data-Extraction Template Items

\begin{tabular}{|c|c|c|}
\hline $\begin{array}{c}\text { Demographics and Additional } \\
\text { Reporting Items }\end{array}$ & Quality Intervention (TIDieR parameters) & QI Technique \\
\hline $\begin{array}{l}\text { 1. Author, year, country, surgical } \\
\text { speciality, setting } \\
\text { 2. Use of patient-reported outcomes } \\
\text { 3. Report use of SQUIRE } \\
\text { guidelines? } \\
\text { 4. Two-year impact factor } \\
\text { 5. Five-year impact factor } \\
\text { 6. Journal quartile rank } \\
\text { 7. Adverse events (unfavorable or } \\
\text { unintended effects) } \\
\text { 8. Presence and type of patient and } \\
\text { public involvement (collaborative } \\
\text { or consultative) }\end{array}$ & $\begin{array}{l}\text { 1. Brief name } \\
\text { 2. Why: rationale for intervention } \\
\text { 3. What: materials used to apply the intervention } \\
\text { 4. What: procedures undertaken } \\
\text { 5. Who: provided the intervention, including level of training } \\
\text { 6. How: the interventions were delivered (e.g., face to face, } \\
\text { Internet) } \\
\text { 7. Where: location (e.g., emergency or elective, and primary or } \\
\text { secondary care) } \\
\text { 8. When and how much: duration, dose, intensity } \\
\text { 9. Modifications: to intervention over course of study } \\
\text { 10. How well (planned): strategies to improve or maintain } \\
\text { intervention compliance } \\
\text { 11. How well (actual): the extent to which the intervention was } \\
\text { delivered as designed }\end{array}$ & $\begin{array}{l}\text { 1. Name of QI technique } \\
\text { 2. Baseline measurement } \\
\text { 3. Data collection schedule } \\
\text { 4. Data analysis (e.g., driver } \\
\text { diagrams) } \\
\text { 5. Data volume/duration (e.g., } \\
\text { length of PDSA cycle) } \\
\text { 6. Explicit description of prediction } \\
\text { of change } \\
\text { 7. Missing data (and reasons given) } \\
\text { 8. Description of generalizability } \\
\text { 9. Named primary outcome }\end{array}$ \\
\hline
\end{tabular}

article once against each TIDieR item, regardless of the number of interventions.

\section{Use of the Checklist of Additional Items (Table 2) to Assess Reporting of QI Techniques}

TIDieR was designed to aid assessment of the reporting of interventions. We also required a means of evaluating the reporting of QI techniques. We decided to score the QI techniques (items 10 and 11 in Table 1) in the studies in our sample by using a checklist of relevant items (Table 2). The checklist items were based on the Cochrane EPOC review group's data-collection checklist, ${ }^{41}$ which had previously been used in systematic reviews to consider reporting features specific to QI measurement. ${ }^{42}$ We selected relevant items from the EPOC checklist, including, for example, baseline measurement, data-collection schedule, data analysis, missing data, and named outcomes, for our checklist. A further item relating to data volume/duration was added in response to a recent publication by Taylor and colleagues ${ }^{16}$ on the reporting of PDSA cycles.

\section{Additional Reporting Features Included in the Data-Extraction Template}

As well as the TIDieR checklist and the checklist of QI techniques, we also included in our data-extraction template items relating to reporting of patient and public involvement (PPI), adverse events, patient-reported outcomes, and use of the Standards for QUality Improvement Reporting Excellence (SQUIRE) guidelines ${ }^{43}$ (Table 2). PPI, defined as the incorporation of the knowledge, skills, and experience of patients, care- givers, and the public into a study, ${ }^{44}$ was included because it is encouraged across all types of surgical interventional studies. ${ }^{45}$ We defined an adverse event as any unfavorable or unintended sign, symptom, or event associated with the intervention; reporting of such events is important to enable the full understanding of possible benefits and harms of interventions. ${ }^{15,45}$ The SQUIRE guidelines, which support the quality of reporting of QI studies, are recommended by the EQUATOR Network.

\section{Absent Reporting Features}

In view of best-practice recommendations produced by the Centre for Reviews and Dissemination, University of York,we also report what was not reviewed as part of this systematic review. Methodological flaws and risk of bias were not examined because the review did not focus on intervention effect. ${ }^{47}$

\section{Data Extraction}

Data extraction and scoring of all data was undertaken [by E.L.J.], after which, to enhance rigor, the data-extraction template was used [by N.L.] to independently score 12 full-text articles. Discrepancies were resolved with a third reviewer [M.D-W.]. Single-data extraction was then performed for all 100 articles [by E.L.J.], and completed scores were reviewed and the data extraction was verified [by N.L.]. Discrepancies that could not be resolved were then discussed [with G.M. and M.D-W.].

\section{Results}

The Preferred Reporting Items for Systematic Reviews and MetaAnalyses (PRISMA) diagram (Figure 1, page 201) reports the 
phases of article identification and selection. The search strategy identified 16,103 abstracts from database searches and 19 from other sources. After duplicates were removed, and 13,603 articles were excluded following initial screening, 1,115 potentially relevant articles were available. Two reviewers [E.L.J., N.L.] independently assessed titles and abstracts of these articles (in discussion with [G.M. or M.D-W.] when discrepancies arose) against the inclusion criteria, resulting in the full text being obtained for 223 articles. Of these 223 articles, 123 were excluded because they were: not written in English $(n=3)$; not QI (83), reviews, or conference abstracts (8); not surgery (24); unobtainable (2); or were cadaver studies (3). On completion of this process, 100 articles were deemed eligible for inclusion.

\section{Study Characteristics}

Of the 100 eligible articles, 40 focused on two or more surgical specialties. The remaining 60 articles named a specialtycardiothoracic (21), colorectal/general (19), musculoskeletal (4), vascular (4), urology (3), gynecology (3), ophthalmology (2), hepatobiliary (1), upper gastrointestinal (1), transplant (1), and otorhinolaryngology (1). Settings included emergency (6), emergency and elective (13), and elective surgery (81).

Study designs were varied (Appendix 2, available in online article). Many articles (65) did not explicitly identify their study design but on inspection were found to be before-and-after studies (a design using data collected at defined time points before and after the introduction of an intervention, also known as the pretest/posttest design). ${ }^{48} \mathrm{Nine}$ studies were labeled as cohort ${ }^{49-57}$ yet did not appear to feature true observational study designs, and one study was mislabeled as a case-control. ${ }^{58}$ The United States was the most frequently reported country for study setting (67/100).

The most commonly reported targeted clinical issue for undertaking QI was that of reducing infection (30), followed by improving intraoperative clinical processes (such as reducing "never events") (18) and reducing postoperative complications (such as bleeding and prolonged intubation) (15). The least frequently cited aims were improving the postoperative discharge process (3), improving self-management (3), and reducing the postoperative incidence of venous thromboembolism (1) (Appendix 3, available in online article).

\section{Completeness of Reporting: QuALity InTERVENTIONS AND Quality Improvement TeChNiQues}

In this section, we report our appraisal of the completeness of reporting of the TIDieR checklist items and QI techniques (Table 2). A full list of all 100 included articles can be found in

\section{Flow Diagram of the Phases of the Systematic Review}

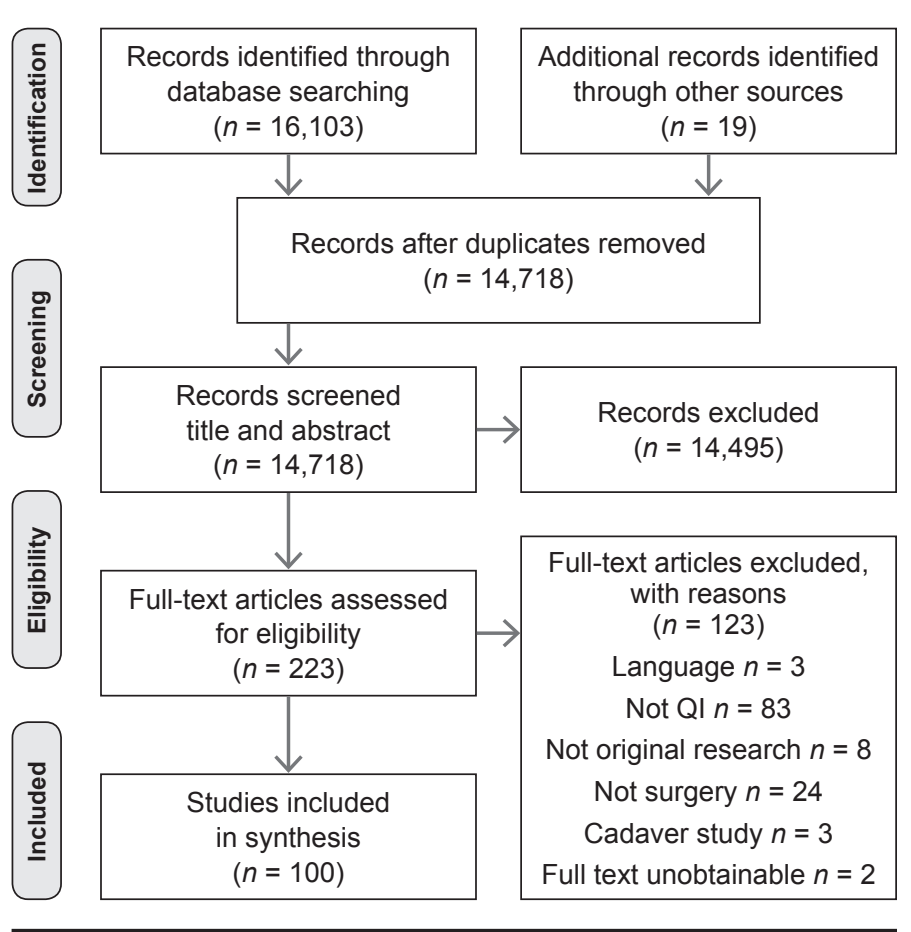

Figure 1. This flow diagram provides the phases of article identification and selection, which resulted in the identification of 100 articles that were deemed eligible for inclusion. Prepared in accordance with Moher D, et al. Preferred reporting items for systematic reviews and meta-analyses: The PRISMA statement. J Clin Epidemiol. 2009;62:1006-1012.

Appendix 4 (available in online article).

Completeness of Reporting: Quality Interventions (TIDieR). All articles used a combination of quality interventions, such as introducing a care pathway, providing staff education, changing the timing of ward rounds, and issuing reminders. No specific combination of interventions was used more often than any other. The most commonly reported intervention (classified according to the modified Shojania et al. QI taxonomy ${ }^{30}$ ) was education (59\% of articles), including any form of teaching and learning, such as workshops. Nine studies provided access to Web links for additional material such as Web-based educational modules. Checklists were reported as quality interventions in $14 \%$ of articles; protocols were reported as quality interventions in $43 \%$. More than half $(51 \%)$ of the studies included feedback as part of the quality intervention.

The distribution of TIDieR scores for the reporting of quality interventions across the 100 articles approximately followed a normal bell-shaped curve, with a slight skew toward higher ratings (Figure 2, page 202). The most common (modal) score was 
$7 / 11$, and the average (arithmetic mean) score was 6.31/11. The TIDieR items that were most usually fully reported were why (complete in $98 \%$ of articles), brief name of intervention (complete in $94 \%$ of articles), where (complete in $77 \%$ of articles), what (procedures) (complete in $69 \%$ of articles), and who (complete in 52\% of articles) (Figure 3, page 203).

How well the researchers actually adhered to the intervention protocol and reported intervention fidelity (item 11: how well actual, Table 2) was the most frequently incomplete TIDieR item (Figure 3), absent in $74 \%$ of the articles. An example of good reporting of intervention fidelity is provided in Thomassen et al.: "Our checklist was used in $61 \%$ of all anaesthesias during the testing period." 59 (p. 1183)

Modifications to interventions were also generally poorly reported (incomplete in $73 \%$ of the articles). Other items that were not fully reported in more than half of the included articles were: what (materialsany physical or informational materials used in the intervention and details on how they can be accessed) (incomplete in $62 \%$ of articles), when and how much (incomplete in 60\% of articles), and how well (planned) (incomplete in 53\% of articles).

Only one article was judged fully complete against the 11 TIDieR items. ${ }^{60}$ Extracts of text from this article (Appendix 5, available in online article) serve as examples of each completely reported TIDieR item.

Completeness of Reporting: QI Technique. The QI techniques most frequently reported in the articles were audit and feedback (42\%), PDSA (28\%), Six Sigma (16\%), continuous quality improvement (CQI) (16\%), and statistical process control (SPC) (10\%).

Assessed against the QI technique criteria (Table 2), the most frequently complete items were naming the QI technique (fully reported in $95 \%$ of the articles) and outcome measures (86\%). The most common incomplete items were the description of missing data (not complete in $83 \%$ of the articles) and the provision of a primary outcome measure (missing in $90 \%$ of the articles) (Figure 4, page 203). This was followed by incomplete reporting of an explicit prediction of change (78\%) and data volume (for example, length and number of PDSA cycles)
(74\%). Just over a third (38\%) of articles discussed whether or not the results might be transferrable to another setting (Figure 4).

Additional Study Features. Use of the SQUIRE guidelines was reported in only one article. ${ }^{58}$ Only two articles - both in the area of orthopedic surgery-reported PPI. In the first of these, Robarts et al. interviewed patients to identify research priorities and service needs and involved patients in a process-mapping exercise. ${ }^{61}$ In the second, Rycroft-Malone et al. collaborated with a patient coresearcher throughout the conduct of the study. ${ }^{62}$ Six studies used patient-reported outcomes in the form of nonvalidated visual analogue pain or patient satisfaction scales. ${ }^{61,63-67}$ One study reported adverse events of the QI intervention-nurses and residents reported anxiety about implementing the intervention. ${ }^{60}$

\section{Discussion}

Adequate reporting and methodology are required to enhance the contribution that QI studies could make to improving care and reducing harm ${ }^{14,37}$ for the millions of patients undergoing surgery each year. ${ }^{68,69}$ Full descriptions are important to determine whether an intervention can be replicated and used to deliver a positive effect in a new setting, as well as what resources 


\section{Template for Intervention Description and Replication (TIDieR) Scores by Items 1-11 for the 100 Perioperative Quality Improvement Articles}

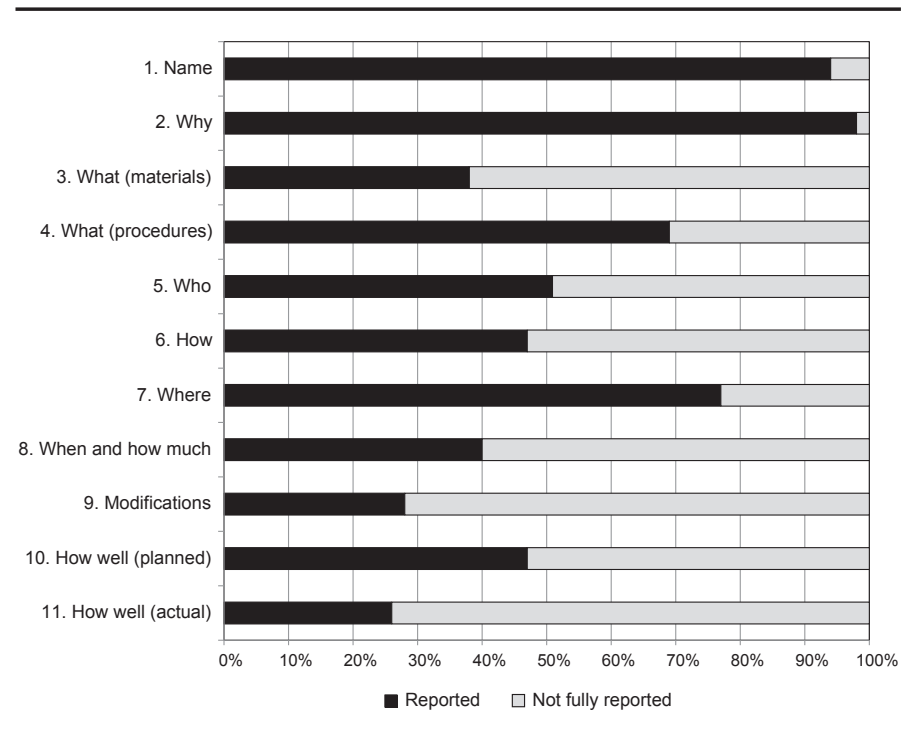

Figure 3. The TIDieR items that were most usually fully reported were why (complete in 98\% of articles), brief name of intervention (94\%), where (77\%), what (procedures; 69\%), and who (52\%).

\section{Quality Improvement (QI) Technique Scores for the 100 Perioperative QI Articles}

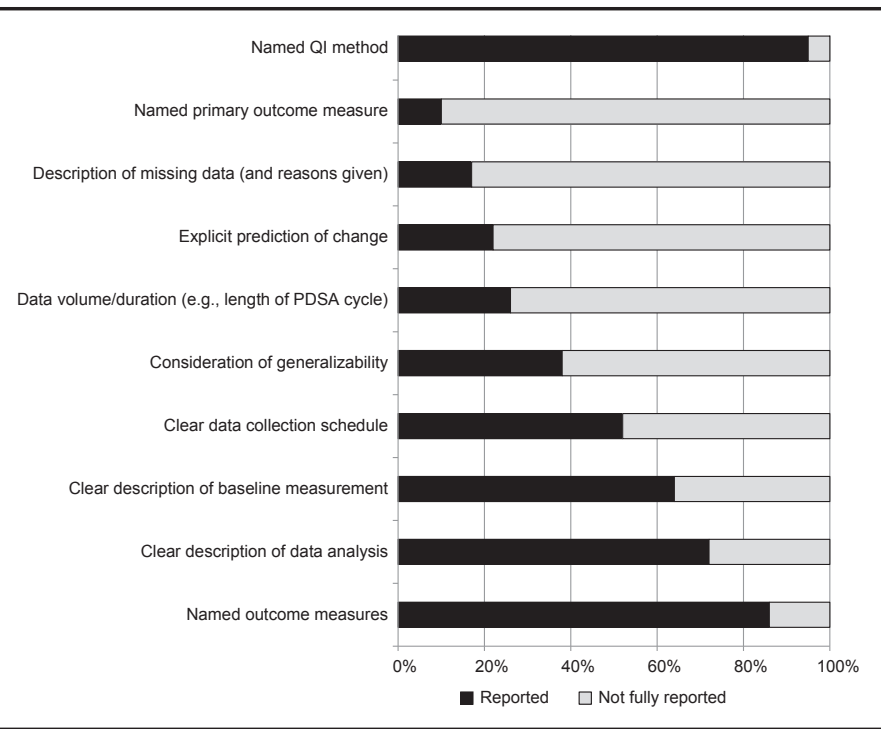

Figure 4. The most frequently complete QI technique items were: naming the QI technique (fully reported in 95\% of the articles) and outcome measures (86\%). The most common incomplete items were the description of missing data (incomplete in $83 \%$ of the articles) and the provision of a primary outcome measure (missing in 90\% of the articles). PDSA, PlanDo-Study-Act. are required and how they should be allocated, and, ultimately, to ensure that patients benefit. ${ }^{17,38}$ Our systematic review has demonstrated that the reporting of $\mathrm{QI}$ in the perioperative care literature is suboptimal (Figure 2), with important details often lacking. More than a third (35\%) of the articles scored $\leq 5$ out of a maximum of 11 (Figure 2) on completeness of intervention reporting. The poor quality of reporting of QI studies identified here is likely to lead to frustration for interested readers.

Complete reporting is necessary to ascertain whether an intervention can be replicated, but it has another equally important function, which is that of informing decisions about whether an intervention should be replicated. ${ }^{70}$ When the results of QI studies are compelling and interesting, interventions must be reported in a way that allows recognition of all of their strengths and weaknesses. Explicit description will help the reader to understand how much the intervention might contribute toward changing practice for the better across many settings and the notable caveats. It was therefore particularly disappointing that we found only one study reporting adverse events resulting from applying the QI intervention.

Incomplete reporting is, among many other problems, also implicated in research waste. Studies that are not fully reported can necessitate additional or futile research that would not be required if the full findings were known. The drive to reduce waste has already been embraced in surgery with initiatives such as the "restoring invisible and abandoned trials" (RIAT) initiative, ${ }^{71}$ which encourages the publication of all research outcomes, and the IDEAL collaborative, ${ }^{22}$ which encourages the publication of accurate and transparent intervention development with the aim of avoiding waste through suboptimal reporting or distortion.

Although our aim in this review was to assess the completeness of reporting of QI, we also identified problems in the reporting of studies themselves. Nine articles ${ }^{49-57}$ were incorrectly described as cohort studies because they were not observational (they included interventions aimed at change), ${ }^{72}$ and many others did not explicitly identify the design used. Inappropriate categorization of studies is not unusual ${ }^{73}$ but may be particularly challenging in QI studies in which conventional descriptors derived from epidemiological study designs might not be optimally suited to use of, say, SPC methods. Consistent application of study design terminology is therefore likely to be helpful to QI reporting in the future.

A further challenge is that most studies in our review used designs, such as before-and-after studies, that have weaknesses in controlling for bias and in making causal inferences, if judged by the standards of traditional epidemiology. However, 


\section{The Joint Commission Journal on Quality and Patient Safety}

these designs are characteristic of QI projects. As we noted earlier, QI and traditional research are distinct (though sometimes overlapping) enterprises: QI projects are primarily aimed at securing change in a specific environment, in contrast to research of which the primary purpose is generating new knowledge. ${ }^{21}$ This makes the description of context particularly important, yet details of many aspects of context were missing in the articles we reviewed.

The range of areas targeted by QI in the articles we included was narrow. For example, we identified a paucity of QI studies examining the discharge process, patient information, and handover (handoff) to primary care on discharge, and coordination within and between specialties in emergency care, even though all of these are known to be problematic. ${ }^{74-76}$ Only two articles reported on patient and public involvement, ${ }^{61,62}$ despite encouragement for improvement strategies to include patients, ${ }^{77}$ again suggesting that many opportunities for QI remain to be addressed.

There are limitations to this study. The possible scope of QI literature is wide, as reflected in the fact that it was difficult to pin down an accepted definition of the term. The use of $\mathrm{MeSH}$ terms and keywords has been inconsistent, ${ }^{78}$ and the 100 articles themselves used myriad terms. There is also no consensual definition of the distinction between quality interventions and QI techniques. The taxonomy we applied was fairly generic and might have resulted in literature being missed or studies being misclassified, although we believe that we reached a good compromise between robustness and pragmatism.

It is a difficult balance for the systematic reviewer to obtain enough articles to ensure that nothing is missed while also reducing "noise" to ensure that the project is manageable. More than 16,000 articles were identified, indicating that our search strategy had low sensitivity and specificity that had to be resolved by detailed review. It is likely that problems in search strategy design were related to lack of consensus on how QI terminology should be applied ${ }^{46}$ and lack of standardization of $\mathrm{MeSH}$ terms for QI article indexing. ${ }^{78}$ It is possible that our search might not have captured all studies stimulated, for example, by the 2014 Improving Trauma Care Act in the United States ${ }^{79}$ or the Emergency and Urgent Care Review in the United Kingdom. ${ }^{80}$ The exclusion of three non-English-language articles and of unpublished reports may have introduced some bias, ${ }^{81}$ but this would have greater importance if the review had intended to estimate the size of the interventions' effect rather than describing their content.

A final limitation of this review is the possibility that reviewers' scoring of the articles might have been imperfect. Overly positive scoring could have occurred if the modification of one element of a multifaceted intervention was scored as "fully reported," when the possibility remains that other modifications were made but went unreported. The reviewers did not contact authors to identify missing aspects of intervention reporting, and the articles were scored as seen. Overly negative scoring might also have occurred. When content was completely absent, the item was scored as not fully reported, but nonreporting might have occurred for good reasons; for example, authors might not have reported on modifications if the intervention was never intended to be modified.

This systematic review has identified suboptimal reporting of QI within surgical literature but did not attempt to identify the possible causes of this problem. It might therefore be necessary to further consider what QI authors believe is required to create an environment in which improved reporting might flourish. The TIDieR checklist, of course, is not designed for assessing reporting of QI articles specifically, and topics for future investigation might include the adaptation of existing reporting guidance, such as TIDieR, to enable better description of features specific to QI. ${ }^{43}$ Benefit might also be gained from exploring journals' word-count limitations, checklist endorsement, and collaborative approaches to learning and sharing information, all of which might offer creative routes to securing fuller reporting. ${ }^{82}$ The key is to identify what is required for authors to generate QI reports that provide a relevant and full account of the QI intervention and technique.

\section{Conclusions}

QI projects in the perioperative literature are suboptimally reported, but it is not yet clear why. Further exploration of poor reporting in surgery may help to orient research toward ways to improve it. This may then contribute toward the development of a comprehensive, coherent, and valid framework for the design and reporting of quality interventions and QI techniques. J

This work has received external funding. It was conducted as part of a Doctoral Research Fellowship funded by The Health Foundation. Graham Martin's contribution to this work was supported by the National Institute for Health Research (NIHR) Collaboration for Leadership in Applied Health Research and Care East Midlands (CLAHRC EM). Mary Dixon-Woods' contribution was supported by Wellcome Trust Senior Investigator Award (grant number WT097899) and by University of Leicester study leave at the Dartmouth Institute for Health Policy and Clinical Practice. The views expressed in this publication are those of the authors and not necessarily those of the National Health Service, the NIHR, or the Department of Health. An oral presentation based on this study was made at the Innovations in Healthcare, Patient Safety and Simulation (Fifth Annual Simulation Conference), Homerton University Hospital, London, Dec 10, 2015. The authors thank Ron T. Hsu, PhD (University of Leicester), for his help in classifying the included articles by study-design type; Jennifer Brosnan, for her help in duplicating the articles; and Tammy Hoffmann, PhD (Bond University, Australia), for her help in applying the TIDieR checklist to the quality improvement studies. 


\section{The Joint Commission Journal on Quality and Patient Safety}

Emma L. Jones, MSc, is a PhD student, University of Leicester, and Orthopaedic Physiotherapist, University Hospitals of Leicester NHS Trust, Leicester. Nicholas Lees, MBChB, FRCA, FFICM, is Consultant in Anaesthesia and Critical Care, Department of Anaesthesia, Royal Brompton and Harefield NHS Foundation Trust, London, and an Honorary Senior Lecturer, Imperial College London. Graham Martin, MA (Oxon), MSc, PhD, is Professor, Health Organisation and Policy, Social Science Applied to Healthcare Improvement Research (SAPPHIRE) Group, and Head, Department of Health Sciences, University of Leicester, United Kingdom. Mary Dixon-Woods, BA, DipStat, MSc, DPhil, is Professor of Medical Sociology, University of Leicester, and Leader, Social Science Applied to Healthcare Improvement Research (SAPPHIRE) Group, University of Leicester. Please address correspondence to Graham Martin, graham.martin@ le.ac.uk.

\section{Online Only Content}

http://www.ingentaconnect.com/content/jcaho/jcjqs

See the online version of this article for

Appendix 1. Search Strategy

Appendix 2. Study Design and Country of Publication Frequency for the 100 Perioperative Quality Improvement Articles

Appendix 3. The 100 Perioperative Quality Improvement Articles, Classified According to Targeted Clinical Issue

Appendix 4. References

Appendix 5. Example of Fully Complete Template for Intervention Description and Replication (TIDieR) Checklist Items

\section{References}

1. National Institute for Health and Care Excellence. Keeping Patients Warm Before, During and After an Operation. Apr 1, 2008. Accessed Mar 31, 2016. https://www.nice.org.uk/guidance/cg65/resources/keeping-patients-warm -before-during-and-after-an-operation-255053003461.

2. Batalden PB, Davidoff F. What is "quality improvement" and how can it transform healthcare? Qual Saf Heal Care. 2007;16:2-3.

3. Institute for Healthcare Improvement. How to Improve. Accessed Mar 22, 2016. http://www.ihi.org/resources/Pages/HowtoImprove/default.aspx.

4. Anderson O, et al. Surgical adverse events: A systematic review. Am J Surg. 2013;206:253-262.

5. Jha AK, et al. Patient safety research: An overview of the global evidence. Qual Saf Health Care. 2010;19:42-47.

6 . Weiser TG, et al. An estimation of the global volume of surgery: A modelling strategy based on available data. Lancet. 2008 Jul 12;372:139-144.

7. Meara JG, Hagander L, Leather AJ. Surgery and global health: A Lancet Commission. Lancet. 2014 Jan 4;383:12-13.

8. Berenguer CM, et al. Improving surgical site infections: Using National Surgical Quality Improvement Program data to institute Surgical Care Improvement Project protocols in improving surgical outcomes. J Am Coll Surg. 2010;210:737-743.

9. Koetsier A, et al. Control charts in healthcare quality improvement: A systematic review on adherence to methodological criteria. Methods Inf Med. 2012;51:189-198.

10. Powell AE, Rushmer RK, Davies HT. A systematic narrative review of quality improvement models in health care. NHS Quality Improvement Scotland. 2009.

11. Steinman MA, et al. Improving antibiotic selection: A systematic review and quantitative analysis of quality improvement strategies. Med Care.
2006;44:617-628

12. Jacquier $I$, et al. The reporting of randomized clinical trials using a surgical intervention is in need of immediate improvement: A systematic review. Ann Surg. 2006;244:677-683.

13. Levy SM, et al. What is the quality of reporting of studies of interventions to increase compliance with antibiotic prophylaxis? J Am Coll Surg. 2013;217:770-779.

14. Ogrinc G, et al. The SQUIRE (Standards for QUality Improvement Reporting Excellence) guidelines for quality improvement reporting: Explanation and elaboration. Qual Saf Health Care. 2008;17 Suppl 1:i13-32.

15. McDonald KM, Schultz EM, Chang C. Evaluating the state of quality-improvement science through evidence synthesis: Insights from the Closing the Quality Gap series. Perm J. 2013;17(4):52-61.

16. Taylor MJ, et al. Systematic review of the application of the plan-do-studyact method to improve quality in healthcare. BMJ Qual Saf. 2014;23:290-298. 17. Hoffmann TC, et al. Better reporting of interventions: Template for Intervention Description and Replication (TIDieR) checklist and guide. BMJ. 2014 Mar 7;348:g1687.

18. Equator Network. About Us. Accessed Mar 22, 2016. http://www.equator-network.org/about-us/.

19. CONSORT. CONSORT Checklist. 2010. Accessed Mar 22, 2016, http:// www.consort-statement.org/checklists/view/32-consort/66-title.

20. Chan AW, et al. SPIRIT 2013 explanation and elaboration: Guidance for protocols of clinical trials. BMJ. 2013 Jan 8;346:e7586.

21. Portela MC, et al. How to study improvement interventions: A brief overview of possible study types. BMJ Qual Saf. 2015;24:325-336.

22. Cook JA, et al. IDEAL framework for surgical innovation 3: Randomised controlled trials in the assessment stage and evaluations in the long term study stage. BMJ. 2013 Jun 18;346:f2820.

23. Blencowe NS, et al. Interventions in randomised controlled trials in surgery: Issues to consider during trial design. Trials. 2015 Sep 4;16:392.

24. Kringos DS, et al. The influence of context on the effectiveness of hospital quality improvement strategies: A review of systematic reviews. BMC Health Serv Res. 2015 Jul 22;15:277.

25. Schulz R, et al. Intervention taxonomy (ITAX): Describing essential features of interventions. Am J Health Behav. 2010;34:811-821.

26. Øvretveit J, Leviton L, Parry G. Increasing the generalisability of improvement research with an improvement replication programme. BMJ Qual Saf. 2011;20 Suppl 1:i87-91.

27. Jones E, et al. Describing methods and interventions: A protocol for the systematic analysis of the perioperative quality improvement literature. Syst Rev. 2014 Sep 5;3:98.

28. University of York, Centre for Reviews and Dissemination. About PROSPERO. (Updated: Jun 29, 2015.) Accessed Mar 22, 2016. http://www .crd.york.ac.uk/PROSPERO/about.asp.

29. Institute of Medicine. To Err Is Human: Building a Safer Health System. Washington, DC: National Academy Press, 2000.

30. Shojania KG, et al. Closing the Quality Gap: A Critical Analysis of Quality Improvement Str)ategies, vol. 1, Series Overview and Methodology. Technical Review 9. Rockville, MD: Agency for Healthcare Research and Quality, 2004. 31. Ellis P, et al. Diffusion and Dissemination of Evidence-Based Cancer Control Interventions: Summary. Evidence Report/Technology Assessment No. 79. Rockville, MD: Agency for Healthcare Research and Quality, 2003.

32. Grimshaw JM, et al. Changing provider behavior: An overview of systematic reviews of interventions. Med Care. 2001;39(8 Suppl 2):112-145.

33. Stone EG, et al. Interventions that increase use of adult immunization and cancer screening services: A meta-analysis. Ann Intern Med. 2002 May 7; 136:641-651.

34. Stafford RS. Alternative strategies for controlling rising cesarean section rates. JAMA. $1990 \mathrm{Feb}$ 2;263:683-687.

35. Weingarten SR, et al. Interventions used in disease management programmes for patients with chronic illness-Which ones work? Meta-analysis of published reports. BMJ. 2002 Oct 26;325:925.

36. Shepperd $S$, et al. Can we systematically review studies that evaluate complex interventions? PLoS Med. 2009;6(8):e1000086. 


\section{The Joint Commission Journal on Quality and Patient Safety}

37. The Health Foundation. Evidence Scan: Improvement Science. Jan 2011. Accessed Mar 22, 2016. http://www.health.org.uk/sites/default/files /ImprovementScience.pdf.

38. Hoffmann TC, Erueti C, Glasziou PP. Poor description of non-pharmacological interventions: Analysis of consecutive sample of randomised trials. BMJ. 2013 Sep 10;347:f3755.

39. Rao N, et al. Prevention of postoperative mediastinitis: A clinical process improvement model. J Healthc Qual. 2004;26(1):22-27.

40. McCulloch P, et al. Effect of a "Lean" intervention to improve safety processes and outcomes on a surgical emergency unit. BMJ. 2010 Nov 2;2;341:c5469.

41. Cochrane Effective Practice and Organisation of Care Review Group. Data Collection Checklist. McAuley L, Ramsay C. Jun 2002. Accessed Mar 22, 2016. http://epoc.cochrane.org/sites/epoc.cochrane.org/files/uploads/datacollectionchecklist.pdf.

42. Grimshaw J, et al. Systematic reviews of the effectiveness of quality improvement strategies and programmes. Qual Saf Health Care. 2003;12:298-303.

43. Davidoff F, et al. Publication guidelines for quality improvement studies in health care: Evolution of the SQUIRE project. BMJ. 2009 Jan 19;338:a3152. 44. INVOLVE: National Institute for Health Research. Public Involvement in Clinical Trials: Supplement to the Briefing Notes for Researchers. Mar 2012. Accessed Mar 22, 2016. http://www.nihr.ac.uk/get-involved/INVOLVEpublic involvementinclinicaltrialsBriefingnotes2012.pdf.

45. Jones EL, et al. Quality of reporting on patient and public involvement within surgical research: A systematic review. Ann Surg. 2015;261:243-250.

46. McDonald KM, Chang C, Schultz E, Through the Quality Kaleidoscope: Reflections on the Science and Practice of Improving Health Care Quality. Closing the Quality Gap: Revisiting the State of the Science. Methods Research Report. Rockville, MD: Agency for Healthcare Research and Quality, 2013. Accessed Mar 22, 2016. https://www.effectivehealthcare.ahrq.gov/ehc/products/509/1406/CQG-Reflections-on-Science-130219.pdf.

47. Centre for Reviews and Dissemination. Systematic Reviews: CRD's Guidance for Undertaking Reviews in Health Care. Jan 2009. Accessed Mar 22, 2016. https://www.york.ac.uk/media/crd/Systematic_Reviews.pdf.

48. Grimshaw J, et al. Experimental and quasi-experimental designs for evaluating guideline implementation strategies. Fam Pract. 2000;17 Suppl 1:S11-16. 49. Larochelle $M$, et al. Diminishing surgical site infections after colorectal surgery with Surgical Care Improvement Project: Is it time to move on? Dis Colon Rectum. 2011;54:394-400.

50. Pronovost PJ, et al. Reducing failed extubations in the intensive care unit. Jt Comm J Qual Improv. 2002;28:595-604.

51. Bloos F, et al. Effects of staff training on the care of mechanically ventilated patients: A prospective cohort study. Br J Anaesth. 2009;103:232-237.

52. Brattebø $\mathrm{G}$, et al. Effect of a scoring system and protocol for sedation on duration of patients' need for ventilator support in a surgical intensive care unit. Qual Saf Health Care. 2004;13:203-205.

53. Taber DJ, et al. Improved patient safety and outcomes with a comprehensive interdisciplinary improvement initiative in kidney transplant recipients. Am J Med Qual. 2013;28:103-112.

54. Stevenson KS, et al. Measurement of process as quality control in the management of acute surgical emergencies. Br J Surg. 2007;94:376-381.

55. Parks JK, et al. Dissecting delays in trauma care using corporate Lean Six Sigma methodology. J Trauma. 2008;65:1098-1105.

56. Duncan F, Haigh C. Measuring and improving the quality of postoperative epidural analgesia for major abdominal surgery using statistical process control charts. J Clin Nurs. 2013;22:2748-2757.

57. Baker RA, Newland RF. Continous quality improvement of perfusion practice: The role of electronic data collection and statistical control charts. Perfusion. 2008;23:7-16.

58. Vetter TR, Ali NM, Boudreaux AM. A case-control study of an intraoperative corneal abrasion prevention program: Holding the gains made with a continuous quality improvement effort. Jt Comm J Qual Patient Saf. 2012;38:490-496.
59. Thomassen $\varnothing$, et al. The effect of a simple checklist on frequent pre-induction deficiencies. Acta Anaesthesiol Scand. 2010;54:1179-1184.

60. Berenholtz SM, et al. Eliminating catheter-related bloodstream infections in the intensive care unit. Crit Care Med. 2004;32:2014-2020.

61. Robarts S, et al. A framework for the development and implementation of an advanced practice role for physiotherapists that improves access and quality of care for patients. Healthc Q. 2008;11(2):67-75.

62. Rycroft-Malone J, et al. A pragmatic cluster randomised trial evaluating three implementation interventions. Implement Sci. 2012 Aug 30;7:80.

63. Gray JR, et al. Elimination of excess perioperative wait time and its impact on immediate clinical outcomes among patients undergoing surgery. J Nurs Care Qual. 2010;25:248-254.

64. Cronin J, et al. Quality improvement pilot program for vulnerable elderly surgical patients. Am Surg. 2011;77:1305-1308.

65. Ramsey C, Ormsby S, Marsh T. Performance-improvement strategies can reduce costs. Health Financ Manage. 2001;Suppl:2-6.

66. Bertolaccini L, et al. 'Six Sigma approach'-An objective strategy in digital assessment of postoperative air leaks: A prospective randomised study. Eur J Cardiothorac Surg. 2011;39:e128-132.

67. Meissner W, Ullrich K, Zwacka S. Benchmarking as a tool of continuous quality improvement in postoperative pain management. Eur J Anaesthesiol. 2006;23:142-148.

68. World Health Organization. WHO Guidelines for Safe Surgery 2009: Safe Surgery Saves Lives. 2009. Accessed Mar 22, 2016. http://whqlibdoc.who.int /publications/2009/9789241598552_eng.pdf.

69. Royal College of Anaesthetists. Perioperative Medicine: The Pathway to Better Surgical Care. 2015. Accessed Mar 22, 2016. https://www.rcoa.ac.uk /sites/default/files/PERIOP-2014.pdf.

70. Øvretveit J. Producing useful research about quality improvement. Int J Health Care Qual Assur Inc Leadersh Health Serv. 2002;15:294-302.

71. Treasure T, et al. Operating to remove recurrent colorectal cancer: Have we got it right? BMJ. 2014 May 13;348:g2085.

72. Song JW, Chung KC. Observational studies: Cohort and case-control studies. Plast Reconstr Surg. 2010;126:2234-2242.

73. Dekkers OM, et al. Distinguishing case series from cohort studies. Ann Intern Med. 2012 Jan 3;156(1 Pt 1):37-40.

74. Francis R. Report of the Mid Staffordshire NHS Foundation Trust Public Inquiry, vol. 3: Present and Future Annexes. London: The Stationary Office, 2013. 75. University Hospitals of Leicester. Leicester, Leicestershire and Rutland (LLR) Joint Primary and Secondary Care Mortality Review. Hsu R, DouglasPannett L. Jul 24, 2014. Accessed Mar 22, 2016. http://www.leicestershospitals .nhs.uk/EasySiteWeb/GatewayLink.aspx?alId=27827).

76. National Health Service. Review into the Quality of Care and Treatment Provided by 14 Hospital Trusts in England: Overview Report. Keogh B. Jul 16, 2013. Accessed Mar 22, 2016. http://www.nhs.uk/nhsengland/bruce-keogh -review/documents/outcomes/keogh-review-final-report.pdf.

77. National Institute for Health and Care Excellence. Prevention and Control of Healthcare-Associated Infections. NICE Guidelines (PH36). Nov 2011. Accessed Mar 22, 2016. https://www.nice.org.uk/guidance/ph36.

78. Hempel $S$, et al. Identifying quality improvement intervention publications-A comparison of electronic search strategies. Implement Sci. 2011 Aug $1 ; 6: 85$.

79. Congress.gov. H.R.3548-Improving Trauma Care Act of 2014. Aug 8, 2014. Accessed Mar 22, 2016. https://www.congress.gov/bill/113th-congress /house-bill/3548.

80. National Health Service (NHS). Transforming Urgent and Emergency Care Services in England: Urgent and Emergency Care Review End of Phase 1 Report. Leeds, UK: NHS, 2013.

81. Jüni $P$, et al. Direction and impact of language bias in meta-analyses of controlled trials: Empirical study. Int J Epidemiol. 2002;31:115-123.

82. Stevens A, et al. Relation of completeness of reporting of health research to journals' endorsement of reporting guidelines: Systematic review. BMJ. 2014 Jun 25;348:g3804. 


\section{Online Only Content}

\section{Appendix 1. Search Strategy}

\section{Combine box $A$ and box $B$ using AND}

\section{BOX A}

Deming.ti,ab, 6 sigma.mp. , (Six adj1 sigma).mp Lean adj1 sigma).mp. , Measurement for improvement.ti,ab, (quality adj2 improv\$).ti,ab., (quality adj1 management).ti,ab., (improv\$ adj2 science).ti,ab., (process adj2 improv\$).ti,ab, (Plan and do and study).ti,ab., PDCA.ti,ab, pdsa.ti,ab., plan do check.ti,ab, (method adj2 improv\$).ti,ab, health.mp. and behavioural economics.ti,ab, operations research.ti,ab, decision science.ti,ab, Shewhart.ti,ab., Pareto chart.ti,Ab, Statistical process control.mp., Statistical quality control.mp, Toyota.mp., Paretochart\$.mp, Control chart.mp.

\section{BOX B}

preoperative.mp., Per-operative.mp., surg\$.ti,ab, exp General Surgery/, exp Surgical Procedures, Operative/, Operative Time/, Peri-operative.ti,ab., Perioperative.ti,ab., Pre-operative.ti,ab, Operative.ti,ab. Cancer\$.mp., enhanced recovery.ti,ab., eras.ti,ab., rapid recovery.ti,ab., fast.mp. and track.ti,ab., Operating theatre.mp, Operating room.mp, Operating room\$.mp, Anesthe\$.mp, Anaesthe\$.mp, Trauma.mp.

\section{Combine using AND to either BOX C or BOX D}

\section{BOX C: Quantitative terms}

Radnomized.ti,ab, Randomi?ed controlled trial.pt., Randomized controlled trial.pt, controlled clinical trial.pt., Randomized controlled trials.sh., random allocation.sh., double blind method.sh., single-blind method.sh., Single?blind method.sh, clinical trial.pt., exp clinical trial/, (clinic\$ adj25 trial\$).ti,ab., ((singl\$ or doubl\$ or trebl\$ or tripl\$) adj25 (blind\$ or mask\$)).ti,ab., placebos.sh., placebo\$.ti,ab., comparative study.sh., exp evaluation studies/, prospective studies.sh., (control\$ or prospective\$ or volunteer or retrospective\$).ti,ab., interrupted time?series, Time-series.ti,ab, Repeated measure\$ .mp. , Cohort.mp., “Case?control”.mp., "case control”.mp. , (assess\$ adj3 process quality).mp, (evaluat\$ adj3 process quality).mp., compliance.ti,ab., quality control.mp, Process control.ti,ab, Control chart*.ti,ab, Adherence OR adherance.ti,ab, group adj3 compar*.mp, Control.ti,ab, Before adj2 after.mp., eval.\$.ti,ab, Variability OR variation OR variable.mp., Checklist\$.mp.

\section{BOX D: Qualitative terms}

Qualitative.ti,ab. , Focus Groups.mp. or exp Focus Groups/ , exp Interview/ or interview.mp. , Interviews as Topic.mp. or exp Interviews as Topic/ , ethnograph\$.mp. , content analysis.mp. , grounded theory.mp, grounded approach.mp. , exp Qualitative Research/ or qualitative.mp., Phenomenolog\$.mp. , discourse analysis.mp. , constant comparison.mp., observational method.mp , theoretical sampl\$.mp. , thematic analys?s.mp. , improvement report\$.mp. 
The Joint Commission Journal on Quality and Patient Safety

\section{Online Only Content}

\section{Appendix 2. Study Design and Country of Publication Frequency for the 100 Perioperative Quality Improvement Articles}

\begin{tabular}{|c|c|}
\hline Study Design & No. of Articles \\
\hline $\begin{array}{l}\text { Uncontrolled before and after (including } \\
\text { statistical process control studies) }\end{array}$ & 85 \\
\hline Nonrandomized controlled interventional study & 4 \\
\hline Cluster randomized trial & 4 \\
\hline Randomized controlled trial & 2 \\
\hline Case series & 2 \\
\hline Time series or segmented time series & 2 \\
\hline Cohort & 1 \\
\hline Country of Publication & No. of Articles \\
\hline United States & 67 \\
\hline Netherlands & 7 \\
\hline United Kingdom & 5 \\
\hline Germany & 4 \\
\hline Australia & 3 \\
\hline Norway & 3 \\
\hline Finland & 1 \\
\hline Taiwan & 1 \\
\hline Iran & 1 \\
\hline Africa & 1 \\
\hline Turkey & 1 \\
\hline Colombia & 1 \\
\hline China & 1 \\
\hline India & 1 \\
\hline Switzerland & 1 \\
\hline France & 1 \\
\hline Italy & 1 \\
\hline
\end{tabular}




\section{The Joint Commission Journal on Quality and Patient Safety}

\section{Online Only Content}

\begin{tabular}{|c|c|}
\hline \multicolumn{2}{|c|}{$\begin{array}{c}\text { Appendix 3. The } 100 \text { Perioperative Quality Improvement Articles, } \\
\text { Classified According to Targeted Clinical Issue* }\end{array}$} \\
\hline Intended Clinical Outcome & No. of Articles \\
\hline Reduce postoperative complications-VTE & 1 \\
\hline $\begin{array}{l}\text { Improve postoperative process—organizational (e.g., discharge process, complication } \\
\text { reporting) }\end{array}$ & 3 \\
\hline Improve self-management/patient and family satisfaction & 3 \\
\hline Reduce postoperative error (e.g., medication errors, unnecessary tests) & 4 \\
\hline Reduce postoperative complications-pain and sedation & 5 \\
\hline Improve preoperative process (e.g., fasting, admissions documentation) & 9 \\
\hline Improve intraoperative process—organizational (e.g., start time, waiting time between cases) & 12 \\
\hline $\begin{array}{l}\text { Reduce postoperative complications—general (e.g., hyponatremia, leak rate, lengthy } \\
\text { intubation) }\end{array}$ & 15 \\
\hline Improve intraoperative process_clinical (e.g., operative technique, never event) & 18 \\
\hline Reduce postoperative complications-infection & 30 \\
\hline $\begin{array}{l}\text { VTE, venous thromboembolism. } \\
\text { * Each article was assigned to the category that represents the targeted clinical issue; some articles may a } \\
\text { of the other listed issues. }\end{array}$ & ddressed one or $m$ \\
\hline
\end{tabular}




\section{The Joint Commission Journal on Quality and Patient Safety}

\section{Online Only Content}

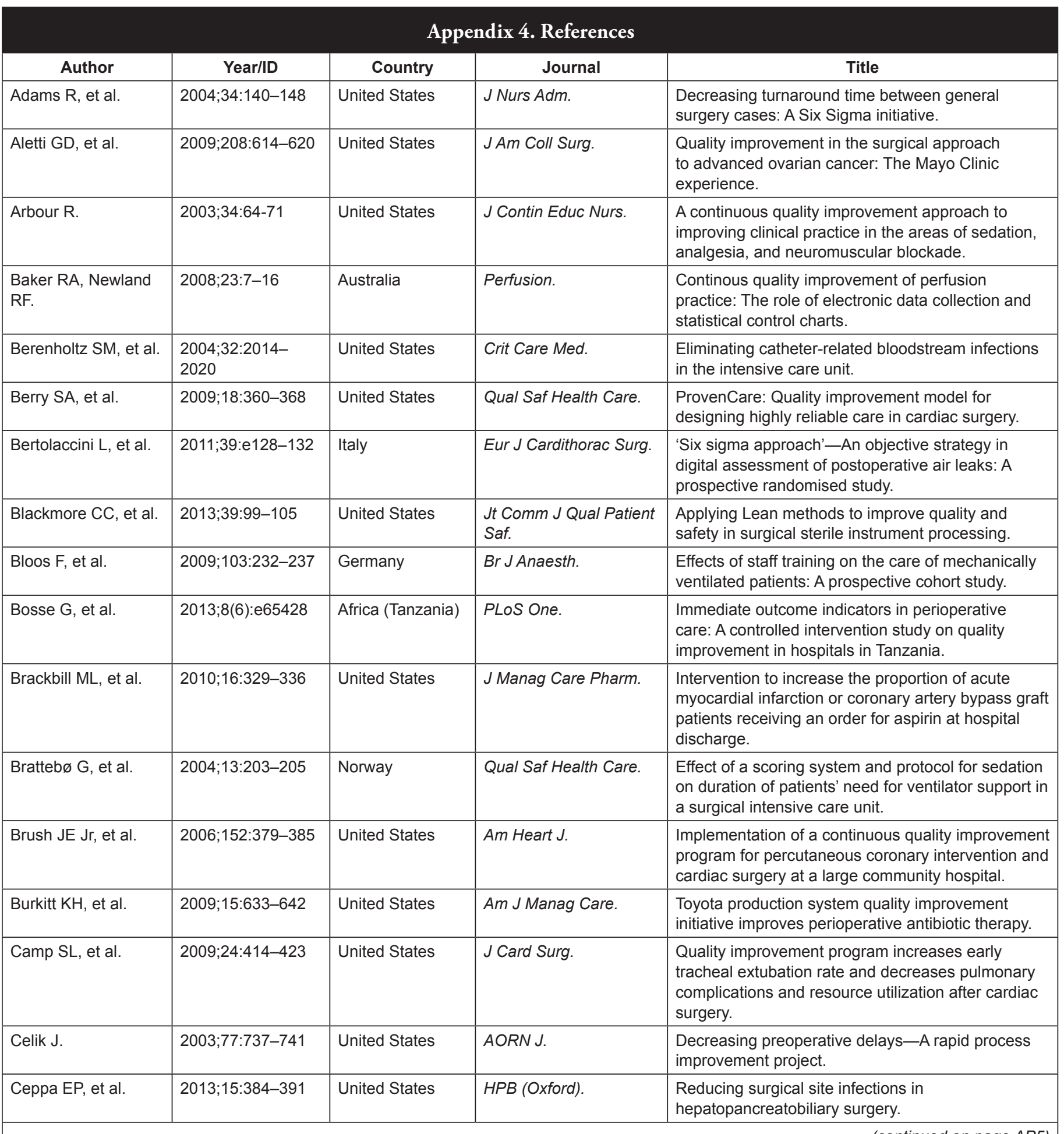

(continued on page AP5) 


\section{Online Only Content}

\begin{tabular}{|c|c|c|c|c|}
\hline \multicolumn{5}{|c|}{ Appendix 4. References (continued) } \\
\hline Author & Year/ID & Country & Journal & Title \\
\hline Cima RR, et al. & 2013;216: 23-133 & United States & J Am Coll Surg. & $\begin{array}{l}\text { Colorectal surgery surgical site infection reduction } \\
\text { program: A national surgical quality improvement } \\
\text { program-driven multidisciplinary single-institution } \\
\text { experience. }\end{array}$ \\
\hline Cima RR, et al. & $2011 ; 213: 83-92$ & United States & J Am Coll Surg. & $\begin{array}{l}\text { Use of Lean and Six Sigma methodology to improve } \\
\text { operating room efficiency in a high-volume tertiary- } \\
\text { care academic medical center. }\end{array}$ \\
\hline Cima RR, et al. & $2009 ; 35: 123-132$ & United States & $\begin{array}{l}\text { Jt Comm J Qual Patient } \\
\text { Saf. }\end{array}$ & $\begin{array}{l}\text { A multidisciplinary team approach to retained } \\
\text { foreign objects. }\end{array}$ \\
\hline Collar RM, et al. & $2012 ; 214: 928-936$ & United States & J Am Coll Surg. & Lean management in academic surgery \\
\hline Crolla RM, et al. & 2012;7(9):e44599 & The Netherlands & PLoS One. & $\begin{array}{l}\text { Reduction of surgical site infections after } \\
\text { implementation of a bundle of care. }\end{array}$ \\
\hline Cronin J, et al. & $\begin{array}{l}2011 ; 77: 1305- \\
1308\end{array}$ & United States & Am Surg. & $\begin{array}{l}\text { Quality improvement pilot program for vulnerable } \\
\text { elderly surgical patients. }\end{array}$ \\
\hline Does RJM, et al. & 2009;41:95-109 & The Netherlands & J Qual Technol. & Reducing start time delays in operating rooms \\
\hline Duclos A, et al. & $2009 ; 96: 171-174$ & France & Br J Surg. & $\begin{array}{l}\text { Quality monitoring in thyroid surgery using the } \\
\text { Shewhart control chart. }\end{array}$ \\
\hline Duncan F, Haigh C. & $\begin{array}{l}2013 ; 22: 2748- \\
2757\end{array}$ & United Kingdom & J Clin Nurs. & $\begin{array}{l}\text { Measuring and improving the quality of } \\
\text { postoperative epidural analgesia for major } \\
\text { abdominal surgery using statistical process control } \\
\text { charts. }\end{array}$ \\
\hline $\begin{array}{l}\text { Dyrkorn OA, } \\
\text { Kristoffersen M, } \\
\text { Walberg M. }\end{array}$ & $2012 ; 21: 206-210$ & Norway & BMJ Qual Saf. & $\begin{array}{l}\text { Reducing post-caesarean surgical wound infection } \\
\text { rate: An improvement project in a Norwegian } \\
\text { maternity clinic. }\end{array}$ \\
\hline Edel, EM. & $2012 ; 95: 228-238$ & United States & $A O R N \mathrm{~J}$. & $\begin{array}{l}\text { Surgical count practice variability and the potential } \\
\text { for retained surgical items. }\end{array}$ \\
\hline $\begin{array}{l}\text { Erdek MA, Pronovost } \\
\text { PJ }\end{array}$ & 2004;16:59-64 & United States & Int J Qual Health Care. & $\begin{array}{l}\text { Improving assessment and treatment of pain in the } \\
\text { critically ill. }\end{array}$ \\
\hline $\begin{array}{l}\text { Ferguson TB Jr, } \\
\text { et al. }\end{array}$ & $2003 ; 290: 49-56$ & United States & JAMA. & $\begin{array}{l}\text { Use of continuous quality improvement to increase } \\
\text { use of process measures in patients undergoing } \\
\text { coronary artery bypass graft surgery: A randomized } \\
\text { controlled trial. }\end{array}$ \\
\hline Forster $\mathrm{DH}$, et al. & 2000;45:302-310 & Germany & J Hosp Infect. & $\begin{array}{l}\text { Can quality circles improve hospital-acquired } \\
\text { infection control? }\end{array}$ \\
\hline Frankel HL, et al. & $2005 ; 201: 349-358$ & United States & J Am Coll Surg. & $\begin{array}{l}\text { Use of corporate Six Sigma performance- } \\
\text { improvement strategies to reduce incidence of } \\
\text { catheter-related bloodstream infections in a } \\
\text { surgical ICU. }\end{array}$ \\
\hline $\begin{array}{l}\text { Goodney PP, Chang } \\
\text { RW, Cronenwett JL. }\end{array}$ & $\begin{array}{l}2008 ; 48: 1481- \\
1488\end{array}$ & United States & J Vasc Surg. & $\begin{array}{l}\text { A percutaneous arterial closure protocol can } \\
\text { decrease complications after endovascular } \\
\text { interventions in vascular surgery patients. }\end{array}$ \\
\hline Gray JR, et al. & 2010;25:248-254 & United States & J Nurs Care Qual. & $\begin{array}{l}\text { Elimination of excess preoperative wait time and } \\
\text { its impact on immediate clinical outcomes among } \\
\text { patients undergoing spinal surgery. }\end{array}$ \\
\hline & & & & (continued on page AP6) \\
\hline
\end{tabular}




\section{The Joint Commission Journal on Quality and Patient Safety}

\section{Online Only Content}

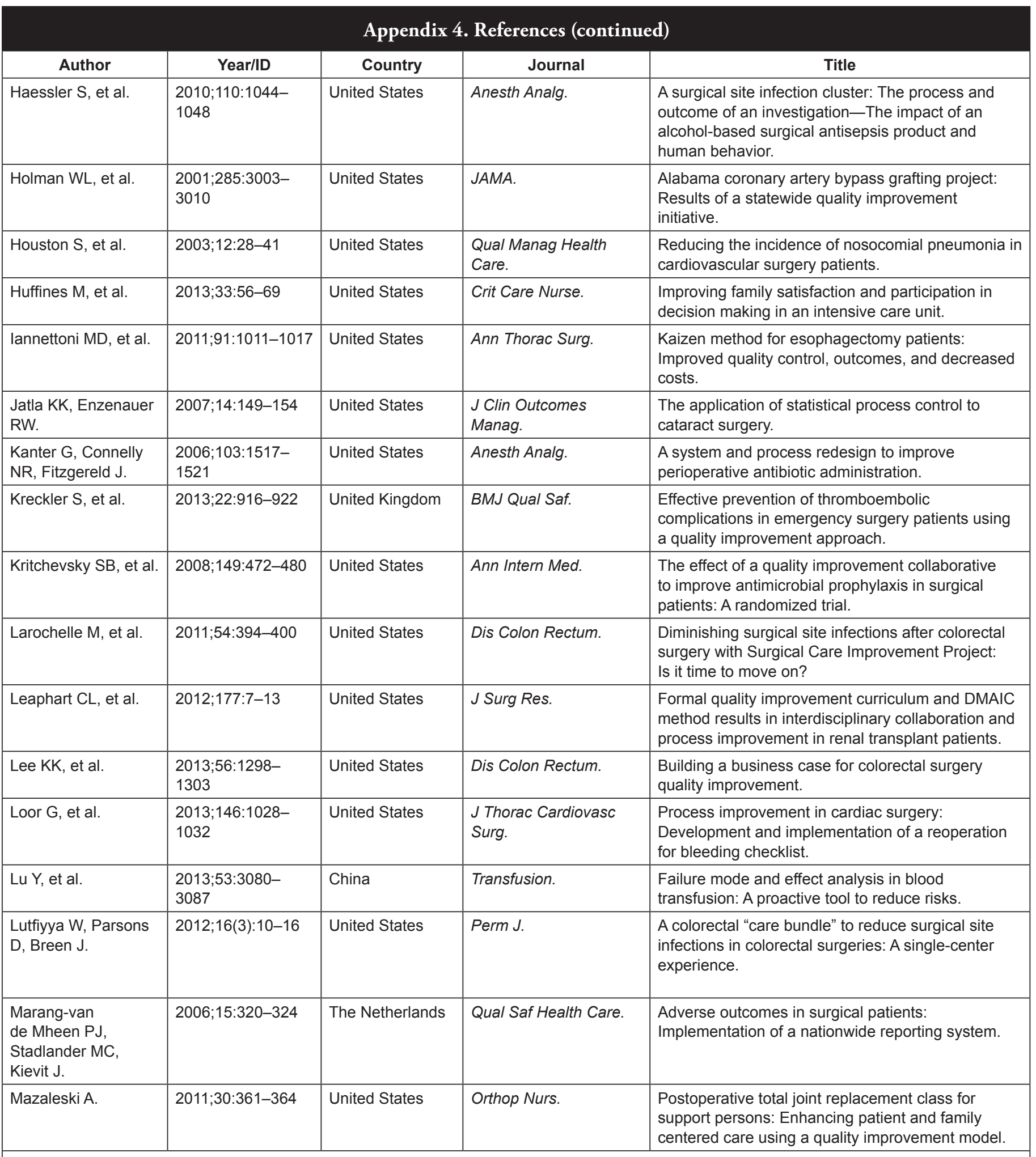




\section{Online Only Content}

\begin{tabular}{|c|c|c|c|c|}
\hline \multicolumn{5}{|c|}{ Appendix 4. References (continued) } \\
\hline Author & Year/ID & Country & Journal & Title \\
\hline McCahill LE, et al. & $2007 ; 142: 355-361$ & United States & Arch Surg. & $\begin{array}{l}\text { Enhancing compliance with Medicare guidelines } \\
\text { for surgical infection prevention: Experience with a } \\
\text { cross-disciplinary quality improvement team. }\end{array}$ \\
\hline McCulloch P, et al. & 2010;341:c5469 & United Kingdom & $B M J$. & $\begin{array}{l}\text { Effect of a "Lean" intervention to improve safety } \\
\text { processes and outcomes on a surgical emergency } \\
\text { unit. }\end{array}$ \\
\hline $\begin{array}{l}\text { Meissner W, Ullrich } \\
\text { K, Zwacka S. }\end{array}$ & $2006 ; 23: 142-148$ & Germany & Eur J Anaesthesiol. & $\begin{array}{l}\text { Benchmarking as a tool of continuous quality } \\
\text { improvement in postoperative pain management. }\end{array}$ \\
\hline Merlani $\mathrm{P}$, et al. & $2001 ; 323: 620-624$ & Switzerland & $B M J$. & $\begin{array}{l}\text { Quality improvement report: Linking guideline to } \\
\text { regular feedback to increase appropriate requests } \\
\text { for clinical tests: Blood gas analysis in intensive } \\
\text { care. [Erratum in BMJ } 2001 ; 323: 993 .]\end{array}$ \\
\hline Navipour $\mathrm{H}$, et al. & 2011;49:38-43 & Iran & Acta Med Iran. & $\begin{array}{l}\text { An investigation into the effects of quality } \\
\text { improvement method on patients' satisfaction: A } \\
\text { semi experimental research in Iran. }\end{array}$ \\
\hline $\begin{array}{l}\text { Newland RF, Baker } \\
\text { RA, Stanley R. }\end{array}$ & 2006;38:139-143 & Australia & J Extra Corpor Technol. & $\begin{array}{l}\text { Electronic data processing: The pathway to } \\
\text { automated quality control of cardiopulmonary } \\
\text { bypass. [Erratum in J Extra Corpor Technol. } \\
2006 ; 38: 370 .]\end{array}$ \\
\hline Niemeijer GC, et al. & 2010;69:614-618 & The Netherlands & J Trauma. & $\begin{array}{l}\text { Quality in trauma care: Improving the discharge } \\
\text { procedure of patients by means of Lean Six Sigma. }\end{array}$ \\
\hline Parker BM, et al. & $2007 ; 104: 140-146$ & United States & Anesth Analg. & $\begin{array}{l}\text { Six Sigma methodology can be used to improve } \\
\text { adherence for antibiotic prophylaxis in patients } \\
\text { undergoing noncardiac surgery. }\end{array}$ \\
\hline Parks JK, et al. & $\begin{array}{l}2008 ; 65: 1098- \\
1104\end{array}$ & United States & J Trauma. & $\begin{array}{l}\text { Dissecting delays in trauma care using corporate } \\
\text { Lean Six Sigma methodology. }\end{array}$ \\
\hline Pronovost PJ, et al. & 2002;28:595-604 & United States & Jt Comm J Qual Improv. & $\begin{array}{l}\text { Reducing failed extubations in the intensive care } \\
\text { unit. }\end{array}$ \\
\hline $\begin{array}{l}\text { Ramsey C, Ormsby } \\
\text { S, Marsh T. }\end{array}$ & 2001;Suppl:2-6 & United States & Healthc Financ Manage. & $\begin{array}{l}\text { Performance-improvement strategies can reduce } \\
\text { costs. }\end{array}$ \\
\hline Rao N, et al. & $2004 ; 26: 22-27$ & United States & J Healthc Qual. & $\begin{array}{l}\text { Prevention of postoperative mediastinitis: A clinical } \\
\text { process improvement model. }\end{array}$ \\
\hline Robarts S, et al. & $2008 ; 11 ; 67-75$ & United States & Healthc $Q$. & $\begin{array}{l}\text { A framework for the development and } \\
\text { implementation of an advanced practice role for } \\
\text { physiotherapists that improves access and quality of } \\
\text { care for patients. }\end{array}$ \\
\hline $\begin{array}{l}\text { Rycroft-Malone J, } \\
\text { et al. }\end{array}$ & $\begin{array}{l}2012 ; 72012 \text { Aug } \\
30 ; 7: 80\end{array}$ & United Kingdom & Implement Sci. & $\begin{array}{l}\text { A pragmatic cluster randomised trial evaluating } \\
\text { three implementation interventions. }\end{array}$ \\
\hline Sandberg WS, et al. & $2008 ; 106: 192-201$ & United States & Anesth Analg. & $\begin{array}{l}\text { Real-time checking of electronic anesthesia } \\
\text { records for documentation errors and automatically } \\
\text { text messaging clinicians improves quality of } \\
\text { documentation. }\end{array}$ \\
\hline Sedlack JD. & $2010 ; 32: 18-26$ & United States & J Healthc Qual. & $\begin{array}{l}\text { The utilization of Six Sigma and statistical process } \\
\text { control techniques in surgical quality improvement. }\end{array}$ \\
\hline $\begin{array}{l}\text { Shukla PJ, Barreto } \\
\text { SG, Nadkarni MS. }\end{array}$ & $2008 ; 55: 311-314$ & India & Hepatogastroenterology. & $\begin{array}{l}\text { Application of Six Sigma towards improving surgical } \\
\text { outcomes. }\end{array}$ \\
\hline
\end{tabular}

(continued on page AP8) 


\section{The Joint Commission Journal on Quality and Patient Safety}

\section{Online Only Content}

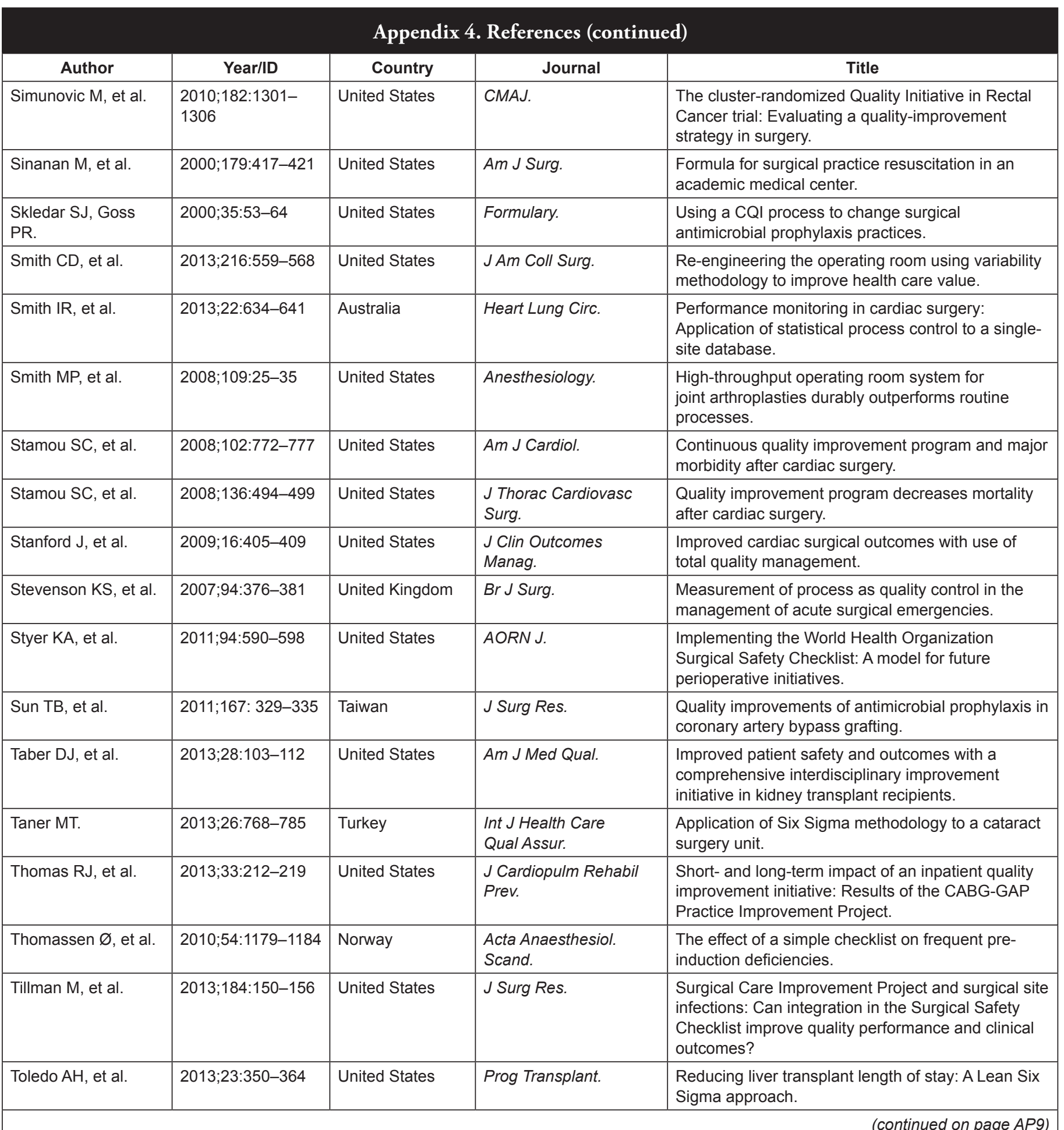




\section{The Joint Commission Journal on Quality and Patient Safety}

\section{Online Only Content}

\begin{tabular}{|c|c|c|c|c|}
\hline \multicolumn{5}{|c|}{ Appendix 4. References (continued) } \\
\hline Author & Year/ID & Country & Journal & Title \\
\hline Torkki PM, et al. & $2006 ; 22: 255-260$ & Finland & $\begin{array}{l}\text { Int J Technol Assess } \\
\text { Health Care. }\end{array}$ & $\begin{array}{l}\text { Managing urgent surgery as a process: Case study } \\
\text { of a trauma center. }\end{array}$ \\
\hline Touijer K, et al. & 2006;49:853-858 & United States & Eur Urol. & $\begin{array}{l}\text { Impact of a multidisciplinary continuous } \\
\text { quality improvement program on the positive } \\
\text { surgical margin rate after laparoscopic radical } \\
\text { prostatectomy. }\end{array}$ \\
\hline van der Slegt J, et al. & 2013;8(8):e71566 & The Netherlands & PLoS One. & $\begin{array}{l}\text { Implementation of a bundle of care to reduce } \\
\text { surgical site infections in patients undergoing } \\
\text { vascular surgery. }\end{array}$ \\
\hline $\begin{array}{l}\text { van Kasteren ME, } \\
\text { et al. }\end{array}$ & $\begin{array}{l}2005 ; 56: 1094- \\
1102\end{array}$ & The Netherlands & $\begin{array}{l}J \text { Antimicrob } \\
\text { Chemother. }\end{array}$ & $\begin{array}{l}\text { Quality improvement of surgical prophylaxis } \\
\text { in Dutch hospitals: Evaluation of a multi-site } \\
\text { intervention by time series analysis. }\end{array}$ \\
\hline van Tiel FH, et al. & $2006 ; 62: 64-70$ & The Netherlands & J Hosp Infect. & $\begin{array}{l}\text { Plan-do-study-act cycles as an instrument for } \\
\text { improvement of compliance with infection control } \\
\text { measures in care of patients after cardiothoracic } \\
\text { surgery. }\end{array}$ \\
\hline $\begin{array}{l}\text { Vetter TR, Ali NM, } \\
\text { Boudreaux AM. }\end{array}$ & $2012 ; 38: 490-496$ & United States & $\begin{array}{l}\text { Jt Comm J Qual Patient } \\
\text { Saf. }\end{array}$ & $\begin{array}{l}\text { A case-control study of an intraoperative corneal } \\
\text { abrasion prevention program: Holding the gains } \\
\text { made with a continuous quality improvement effort. }\end{array}$ \\
\hline Vogel $\mathrm{P}$, et al. & $\begin{array}{l}2011 ; 396: 1009- \\
1015\end{array}$ & Germany & $\begin{array}{l}\text { Langenbecks Arch } \\
\text { Surg. }\end{array}$ & $\begin{array}{l}\text { Morbidity and Mortality conference as part of PDCA } \\
\text { cycle to decrease anastomotic failure in colorectal } \\
\text { surgery. }\end{array}$ \\
\hline Warner CJ, et al. & $\begin{array}{l}2013 ; 58: 1417- \\
1422\end{array}$ & United States & J Vasc Surg. & $\begin{array}{l}\text { Lean principles optimize on-time vascular surgery } \\
\text { operating room starts and decrease resident work } \\
\text { hours. }\end{array}$ \\
\hline Warren CS, et al. & $2011 ; 43: 58-63$ & United States & J Extra Corpor Technol. & $\begin{array}{l}\text { Variation in arterial inflow temperature: A regional } \\
\text { quality improvement project. }\end{array}$ \\
\hline Weinberg M, et al. & $\begin{array}{l}2001 ; 161: 2357- \\
2365\end{array}$ & Colombia & Arch Intern Med. & $\begin{array}{l}\text { Reducing infections among women undergoing } \\
\text { cesarean section in Colombia by means of } \\
\text { continuous quality improvement methods. }\end{array}$ \\
\hline Wick EC, et al. & 2012;215:193-200 & United States & J Am Coll Surg. & $\begin{array}{l}\text { Implementation of a surgical comprehensive } \\
\text { unit-based safety program to reduce surgical site } \\
\text { infections. }\end{array}$ \\
\hline Windle PE, et al. & $2001 ; 6: 38-46$ & United States & $\begin{array}{l}\text { Lippincotts Case } \\
\text { Manag. }\end{array}$ & $\begin{array}{l}\text { A COMIT model utilization to improve first-case start } \\
\text { time. }\end{array}$ \\
\hline Wren SM, et al. & $2010 ; 210: 491-495$ & United States & J Am Coll Surg. & $\begin{array}{l}\text { Postoperative pneumonia-prevention program for } \\
\text { the inpatient surgical ward. }\end{array}$ \\
\hline Zack J. & 2008;36:S176.e1-2 & United States & Am J Infect Control. & $\begin{array}{l}\text { Zeroing in on zero tolerance for central line- } \\
\text { associated bacteremia. }\end{array}$ \\
\hline
\end{tabular}




\section{Online Only Content}

\begin{tabular}{|c|c|c|c|c|c|}
\hline \multicolumn{6}{|c|}{$\begin{array}{l}\text { Appendix 5. Example of Fully Complete Template for Interver } \\
\text { Checklist Items* }\end{array}$} \\
\hline 1 & 2 & 3 & 4 & 5 & 6 \\
\hline Brief Name & WHY: Rationale & WHAT: Materials & WHAT: Procedures & $\begin{array}{l}\text { WHO: Staff Group, } \\
\text { Level of Training } \\
\text { \& Expertise }\end{array}$ & $\begin{array}{l}\text { HOW: Mode of } \\
\text { Delivery }\end{array}$ \\
\hline $\begin{array}{l}\text { "multifaceted } \\
\text { systems intervention" } \\
\text { (p. 2014). }\end{array}$ & $\begin{array}{l}\text { To determine whether } \\
\text { a multifaceted } \\
\text { systems intervention } \\
\text { would eliminate } \\
\text { catheter-related } \\
\text { bloodstream } \\
\text { infections }\end{array}$ & $\begin{array}{l}\text { Web-based training } \\
\text { module (http://www } \\
\text {.hopkins-medicine } \\
\text {.org.heic/), a } \\
\text { standardized checklist } \\
\text { to be used during } \\
\text { central venous } \\
\text { catheter insertion, } \\
\text { a daily goals form, } \\
\text { a central catheter } \\
\text { insertion cart with } \\
\text { four drawers and } \\
\text { partitions to organize } \\
\text { the contents, which } \\
\text { can be rolled to the } \\
\text { patient's room }\end{array}$ & $\begin{array}{l}\text { Five interventions, } \\
\text { including "empower- } \\
\text { ing nurses to stop } \\
\text { the procedure if } \\
\text { guidelines were not } \\
\text { followed" (p. 2016). } \\
\text { An example of } \\
\text { reporting item } 4 \\
\text { (procedure) for this } \\
\text { intervention is: "we } \\
\text { discussed with both } \\
\text { residents and nurses } \\
\text { that the nurse should } \\
\text { page the SICU } \\
\text { attending physician } \\
\text { if the resident, after } \\
\text { the nurse identifies } \\
\text { a violation, fails to } \\
\text { corrrect the violation" } \\
\text { (p. 2016). }\end{array}$ & $\begin{array}{l}\text { "An interdisciplinary } \\
\text { team including the } \\
\text { SICU codirectors, } \\
\text { ICU physicians, } \\
\text { nurses, and infection } \\
\text { control practitioners" } \\
\text { (p. 2015). Additional } \\
\text { information about how } \\
\text { the QI team worked } \\
\text { together included: } \\
\text { "The SICU leadership } \\
\text { met with both groups } \\
\text { of providers and } \\
\text { emphasized our focus } \\
\text { on patient safety and } \\
\text { teamwork" (p. 2018). }\end{array}$ & $\begin{array}{l}\text { "All physicians or } \\
\text { physician extenders } \\
\text { who insert central } \\
\text { catheters were } \\
\text { required to complete } \\
\text { a Web-based } \\
\text { training module and } \\
\text { successfully complete } \\
\text { a ten-question test } \\
\text { before they were } \\
\text { allowed to insert } \\
\text { a central venous } \\
\text { catheter" (p. 2016). }\end{array}$ \\
\hline 7 & 8 & 9 & 10 & 11 & \\
\hline $\begin{array}{l}\text { WHERE: Setting + } \\
\text { Infrastructure }\end{array}$ & $\begin{array}{l}\text { WHEN \& HOW } \\
\text { MUCH: } \\
\text { Dose/Duration }\end{array}$ & Modifications & $\begin{array}{l}\text { HOW WELL: } \\
\text { (Planned) }\end{array}$ & $\begin{array}{l}\text { HOW WELL: } \\
\text { (Actual) }\end{array}$ & \\
\hline $\begin{array}{l}\text { The surgical ICU is a } \\
\text { 16-bed unit for adult } \\
\text { patients undergoing } \\
\text { general, orthopedic, } \\
\text { transplant, trauma, } \\
\text { and vascular surgery. } \\
\text { Extra features of } \\
\text { the setting relevant } \\
\text { to the intervention } \\
\text { included "Hospital } \\
\text { Epidemiology and } \\
\text { Infection Control } \\
\text { (HEIC) required } \\
\text { leaders from hopsital } \\
\text { administration to ... } \\
\text { provide the SICU } \\
\text { with the additional } \\
\text { resources required" } \\
\text { (p. 2018). }\end{array}$ & $\begin{array}{l}\text { From January } 1 \text {, } \\
\text { 1998, through } \\
\text { December 31, 2002, } \\
\text { ALL those who insert } \\
\text { central catheters } \\
\text { were required to } \\
\text { complete a Web- } \\
\text { based training module } \\
\text { (URL provided) and } \\
\text { successfully complete } \\
\text { a } 10-\text { question test. } \\
\text { The checklist was } \\
\text { implemented in } \\
\text { two phases, which } \\
\text { inlcluded a 2-week } \\
\text { observation period. }\end{array}$ & $\begin{array}{l}\text { The management } \\
\text { of central venous } \\
\text { catheters once they } \\
\text { are inserted did not } \\
\text { change during the } \\
\text { study period, with } \\
\text { the exception of } \\
\text { the change in daily } \\
\text { patient visits in the } \\
\text { study SICU to ask } \\
\text { whether catheters } \\
\text { could be removed. } \\
\text { Following a pilot test, } \\
\text { the checklist was } \\
\text { modified based on } \\
\text { feedback received. }\end{array}$ & $\begin{array}{l}\text { Residents were } \\
\text { informed that a } \\
\text { checklist was being } \\
\text { used. This strategy } \\
\text { allowed nurses to } \\
\text { feel more comfortable } \\
\text { intervening if they } \\
\text { observed a violation, } \\
\text { because they felt } \\
\text { that an expectation } \\
\text { had been set and as } \\
\text { a result, they were } \\
\text { less likely to have } \\
\text { an uncomfortable } \\
\text { encounter with } \\
\text { a physician and } \\
\text { they could stop the } \\
\text { procedure if they } \\
\text { saw a violation of } \\
\text { evidence-based } \\
\text { practice. }\end{array}$ & $\begin{array}{l}\text { An example of } \\
\text { actual compliance } \\
\text { with one of the five } \\
\text { interventions: "During } \\
\text { the first month, } \\
\text { nursing completed } \\
\text { the checklist for } 38 \\
\text { procedures: eight } \\
(24 \%) \text { for new central } \\
\text { venous access, } 30 \\
\text { (79\%) for catheter } \\
\text { exchanges over a } \\
\text { wire, and three (8\%) } \\
\text { were emergent. A } \\
\text { nursing intervention } \\
\text { was required in } 32 \% \\
\text { (12/38) of central } \\
\text { venous catheter } \\
\text { insertions" (p. 2017). }\end{array}$ & \\
\hline $\begin{array}{l}\text { ICU, surgical ICU; QI, } \\
\text { Adapted from Berenho }\end{array}$ & improvement. & 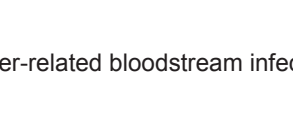 & & & - \\
\hline
\end{tabular}

